\title{
POLÍTICA AMBIENTAL BRASILEIRA: ANÁLISE HISTÓRICO- INSTITUCIONALISTA DAS PRINCIPAIS ABORDAGENS ESTRATÉGICAS
}

\author{
Marcus Bruno Malaquias Ferreira* \\ Alexandre Ottoni Teatini Salles*
}

\begin{abstract}
Resumo: Este artigo apresenta uma análise histórico-institucionalista sobre o processo de evolução das políticas ambientais no Brasil contemporâneo. Essa retrospectiva procura identificar o papel atribuído ao meio ambiente em relação às estratégias de desenvolvimento econômico adotadas pelo Estado, com início a partir da primeira fase da industrialização brasileira nos anos 1930. O exame das abordagens estratégicas predominantes permite ainda analisar as circunstâncias que motivaram a origem, e conduziram a transformações das instituições que se ocupam das questões ambientais no Brasil. Com isso, pretende-se compreender o processo cumulativo que resultou em um sistema institucional de gestão do meio ambiente onde a análise das implicações ambientais da produção ocorre apenas no âmbito de projetos, portanto, afastado dos mecanismos de planejamento de longo prazo.
\end{abstract}

Palavras-chave: Política Ambiental no Brasil. Gestão Ambiental. Desenvolvimento.

\begin{abstract}
This article presents a historical-institutional analysis about the evolution of environmental policies in contemporary Brazil. This retrospective seeks to identify the role attributed to the environment in relation to the strategy of economic development adopted by the State, starting from the first phase of Brazilian industrialization in the 1930s. The investigation of the predominant strategic approaches also allows to analyze the circumstances that motivated the origin, and led to changes in the institutions that deal with environmental issues in Brazil. Thus, we intend to understand the cumulative process that resulted in an institutional system of environmental management where the analysis of the environmental implications of production occurs only in the scope of projects, therefore, away from the long-term planning mechanisms.
\end{abstract}

Keywords: Brazilian Environmental Policy. Environmental management. Development.

\footnotetext{
* Universidade Federal do Espírito Santo
} 


\section{Introdução}

A política ambiental praticada em um país indica o modo como os recursos naturais são utilizados e adequados para o desenvolvimento de atividades econômicas que geram impactos potencialmente degradantes. Este artigo pretende examinar o processo de evolução das políticas ambientais brasileiras a partir da década de 1930. Procura-se com isso investigar o tipo de racionalidade que fomentou as decisões que envolveram a crescente necessidade de produção, vis-à-vis o esgotamento dos recursos naturais que eventualmente provocaram a emergência de uma consciência ambiental.

Essa análise permite identificar as diferentes concepções acerca do meio ambiente e do seu papel em relação às estratégias de desenvolvimento econômico adotadas pelo Estado em cada etapa investigada. Além disso, procura-se distinguir implicações dessas estratégias na esfera institucional para a execução das respectivas políticas ambientais. Trata-se, portanto, de uma análise históricoinstitucionalista da questão ambiental no Brasil.

Vale observar que a maioria dos trabalhos relacionados a política ambiental brasileira toma como ponto de partida a criação da Secretaria Especial do Meio Ambiente na década de 1970. A delimitação das fases das políticas ambientais empregada neste artigo baseou-se predominantemente no trabalho de Monosowski (1989), principalmente devido a sua abrangência, pois esta categorização se inicia a partir dos anos 1930. A autora distingue quatro abordagens estratégicas básicas nas políticas ambientais brasileiras: 1) a administração dos recursos naturais, 2) o controle de poluição industrial, 3) o planejamento territorial e 4) a Política Nacional do Meio Ambiente. O objetivo central desta investigação é entender o processo de formação e institucionalização da política ambiental brasileira e, também, identificar os fatores que influenciaram sua consolidação na forma como é praticada na atualidade.

A fim de cumprir o objetivo proposto, este artigo apresenta-se dividido em seis seções. Além desta seção inicial, da seção um até a cinco serão apresentadas e discutidas criticamente as quatro abordagens estratégicas nas políticas ambientais brasileiras supracitadas. A seção cinco contém uma subseção onde serão apontados aspectos relevantes do processo de institucionalização da Política Nacional do Meio Ambiente, com foco na adoção do "licenciamento ambiental" como principal mecanismo mediador das relações entre a produção e a prevenção, ou mitigação, de impactos ambientais no Brasil. As considerações finais concluem o artigo.

\section{A Primeira Abordagem Estratégica da Política Ambiental no Brasil após a primeira industrialização: a administração dos recursos naturais}

Desde o período colonial a economia brasileira é marcada por ciclos caracterizados pela exploração intensiva de determinados recursos naturais (Furtado, 1959), especialmente o solo, através da agricultura. O avanço das ciências ambientais permite compreender, por exemplo, quão radical pode ser a modificação que a cultura agrícola pode provocar nos ecossistemas. 
Até o início do processo de industrialização no período de reorganização do Estado brasileiro promovido por Getúlio Vargas, a importância atribuída à utilização dos recursos naturais decorria de sua centralidade na atividade produtiva. Isto, portanto, era o elemento essencial que alimentava o processo de tomada de decisão, muito mais do que uma desejável consciência "científica" da importância de preservação do ambiente. Em outras palavras, não havia, até então, uma demanda social, nem mesmo uma consciência ecológica, que justificasse a adoção sistemática de medidas de mitigação ou controle ambiental. Estas ganhariam o primeiro contorno com a intensificação da industrialização nos anos 1930.

Isso não significa que antes deste período não existissem iniciativas no sentido de disciplinar o uso de recursos naturais no Brasil. Sánchez (2008a: 70-2) reúne alguns exemplos de medidas com viés preservacionista adotadas antes da primeira fase da industrialização brasileira. Vale destacar a proibição da utilização de madeiras de lei na indústria da construção naval, por meio de medidas editadas pela Coroa portuguesa no final do século XVIII; a proibição da devastação dos mangues pelo Rei Dom J osé em 1760; nesta mesma época foi relatada reação da Coroa à exploração deletéria das minas de ouro e diamante, dentre outros.

Essas medidas tinham em comum o fato de não fazer parte de uma política sistemática que alcançasse um conjunto de atividades ambientalmente danosas. Entretanto, a necessidade de industrialização ${ }^{1}$ foi determinante para a imposição de uma base regulatória. Esta, posta em prática somente no período getulista (década de 1930). A partir daí, inicia-se a primeira fase das políticas ambientais brasileira, qual seja, a administração dos recursos naturais - segundo a categorização sugerida por Monosowski (1989).

Mediante a urgência pela industrialização, o início das ações governamentais em políticas ambientais no País foi caracterizado pela adoção de uma série de códigos e medidas administrativas. Estas, tinham por objetivo racionalizar o uso e a explotação dos recursos naturais, configurando-se em políticas públicas setoriais que regulamentavam o acesso e a apropriação desses recursos (Sánchez, 2008a). Em caráter suplementar, a estratégia também procurou definir áreas de preservação ambiental. Dentre os principais instrumentos legais adotados destacam-se: a adoção, em 1934, do Código das Águas, do Código da Mineração e do Código Florestal; e também, em 1937, a criação do Parque Nacional de Itatiaia e o advento da legislação para a proteção do patrimônio histórico e artístico nacional.

Nesta etapa, a política ambiental já indicava um aspecto conservacionista, pois a estratégia também se ocupou em definir áreas de preservação ambiental e em criar unidades de conservação. A criação de unidades de conservação poderia

\footnotetext{
${ }^{1}$ Na América Latina, o período entre a Primeira e Segunda Guerra Mundial foi marcado por importantes esforços em termos de industrialização. Os fatos históricos determinantes desta política remetem à necessidade de diversificação nas economias da região para superar a dependência externa. O impulso mais imediato nesse sentido foi a crise de 1930, que induziu os países mais importantes da América Latina (dentre eles o Brasil) a um processo acelerado de substituição de produtos manufaturados de importação (Sunkel; Paz, 1974).
} 
representar uma contradição. Entretanto, esta incoerência é aparente pois a criação de reservas ecológicas e de "áreas-santuário" com fins científicos (para pesquisa, por exemplo) poderia acentuar a disponibilidade à apropriação do território remanescente e de seus recursos naturais para o desenvolvimento de atividades econômicas. Em outras palavras, a criação de unidades de conservação pode ser usada como justificativa para despreocupações ambientais relacionadas à apropriação de recursos naturais nas demais áreas. Desde 1937, foram criados vários parques nacionais e reservas florestais em diversos pontos do território nacional (Monosowski, 1989; Sánchez, 2008a).

A política de "administração dos recursos naturais" ainda refletia uma visão de sistema econômico pouco integrado com as questões ambientais. Ou seja, as potencialidades e restrições naturais não eram adequadamente consideradas nas decisões relacionadas à produção com vistas no longo prazo. A julgar pela opção de desenvolvimento baseada em uma industrialização voltada à exploração intensiva de recursos naturais não renováveis, especialmente minério de ferro e petróleo. Estratégia estas, notadas tanto na primeira industrialização promovida no governo de Getúlio Vargas, como na gestão de J uscelino Kubitschek nos anos 1950 - quando o governo estipulou metas físicas envolvendo o aumento da produção de combustíveis fósseis e produtos primários, por exemplo (Orenstein; Sochaczewski, 2014). Percebeu-se mais tarde que, além de deletério ao meio ambiente, o desenvolvimento industrial promovido no Brasil neste período, bem como em toda a América Latina, não produziu o efeito esperado em relação à redução da dependência externa, nem conseguiu obter capacidade de crescimento sustentado - apesar de ter promovido uma diversificação importante da estrutura produtiva desses países (Sunkel; Paz, 1974).

Embora Cunha e Coelho (2007) delimitem esta primeira etapa das políticas ambientais no Brasil no período compreendido entre 1930 e 1971, portanto, com início e fim, a estratégia de administração dos recursos naturais nunca foi abandonada. Tal estratégia permanece presente nos diversos códigos adotados naquela época que, apesar de reformados, ainda se encontram em pleno vigor.

\section{A Segunda Abordagem Estratégica da Política Ambiental Brasileira: o controle da poluição industrial}

O início desta nova fase, o controle da poluição industrial, foi marcado pela criação da Secretaria Especial do Meio Ambiente (SEMA) por meio do Decreto $n^{\circ}$ 73.030, de 30 de outubro de 1973. Este ato administrativo foi influenciado pelos ideais inovadores da Conferência das Nações Unidas sobre o Meio Ambiente ocorrida em Estocolmo em 1972.

É importante enfatizar que até este momento não havia um órgão voltado exclusivamente à questão ambiental em âmbito nacional. Entretanto, sob o ponto de vista institucional, a criação do órgão não representou de imediato uma mudança na estrutura da tomada de decisão sobre as questões ambientais mais relevantes, em especial, a localização industrial ou tecnologias utilizadas na produção.

Em primeiro lugar, ao criar essa estrutura, o então presidente Emílio G. Médici atendeu a uma demanda diplomática. Nas discussões de Estocolmo, havia de um lado os chamados "catastrofistas" - que anunciavam o "apocalipse" diante da 
continuidade do crescimento econômico e demográfico. De outro, os "otimistas" - que previam que sempre haveria abundância de recursos naturais. De acordo com Sachs (2008), os otimistas diziam que a prioridade do setor produtivo deveria ser dada à aceleração do crescimento, e que as externalidades negativas oriundas desse processo poderiam ser neutralizadas posteriormente, quando os países em desenvolvimento atingissem o nível de renda per capita dos países desenvolvidos. Ao sustentar essa tese, o Brasil criou uma imagem internacional negativa. Por este motivo, a criação da SEMA teve que responder também a questões políticas e de natureza diplomática.

As ações da secretaria apresentavam uma certa limitação quanto ao seu alcance, decorrente da natureza de suas atribuições legais - típicas da administração direta. Assumindo, portanto, caráter muito mais orientativo e acessório do que de executor de políticas públicas. Apesar das limitações, havia espaço para iniciativas inovadoras no campo das políticas ambientais. Como exemplo dessas inovações, é possível identificar no ato de criação da SEMA uma rara tentativa de inserção da variável ambiental no planejamento estratégico no Brasil. O artigo primeiro da norma que criou este órgão - Decreto $n^{\circ}$ 73.030/ 1973 - pode revelar esta característica. Senão vejamos.

$\S 2^{\mathrm{o}}$ - O Ministério do Interior atuará em articulação com o Ministério do Planejamento e Coordenação Geral, que examinará principalmente as implicações, para a conservação do meio ambiente, da estratégia de desenvolvimento nacional e do progresso tecnológico, este último aspecto em coordenação com o Conselho Nacional de Pesquisas (Brasil, Art. 1ㅜ, 1973)

Ao falar de implicações da estratégia de desenvolvimento nacional edo progresso tecnológico para a conservação do meio ambiente, o Decreto cria uma previsão legal para inclusão de questões ambientais no âmbito do planejamento estratégico, ainda quedeuma forma apenas restritiva. No contexto histórico, essa previsão legal representou uma grande inovação. Não obstante, a estrutura político-administrativa vigente não favorecia a implementação de dispositivos legais ou mecanismos de planejamento potencialmente conflitantes com a estratégia de crescimento econômico acelerado - este respeito, vale lembrar que a tônica no momento era a do desenvolvimento em "marcha forçada" (Castro; Souza, 1985). O antagonismo reside no fato de que uma das principais instituições responsáveis pela implantação da estratégia de expansão da estrutura produtiva era o Ministério do Interior, mesmo órgão ao qual era vinculado à SEMA. Considerando que as questões ambientais historicamente são tratadas como externalidades às políticas setoriais que lidam com a atividade produtiva, as ações voltadas ao planejamento ou ao controle ambiental pareciam conflitantes com a política econômica em curso naquele momento.

De fato, notou-se no período um ritmo acelerado de degradação do capital natural. As políticas ambientais não se harmonizam com as políticas modernizantes e com as estratégias de integração nacional implementadas no período militar (Cunha; Coelho, 2007).

Considerando o papel secundário assumido pela SEMA nesta fase da política ambiental brasileira, as ações de controle ambiental tornaram-se um pouco mais explícitas com o advento do Segundo Plano Nacional de Desenvolvimento (II PND) em 1974. Formalmente, o plano contou com um capítulo sobre 
desenvolvimento urbano, controle de poluição e preservação do meio ambiente, onde notou-se prioridade destinada ao controle da poluição industrial. Além disso, observou-se uma política de indução à localização industrial em regiões densamente urbanizadas. Essa estratégia foi consolidada com medidas que autorizava a criação de sistemas de licenciamento para a instalação de atividades industriais potencialmente poluidoras nos Estados e Municípios. Para subsidiar o incipiente controle das fontes poluidoras relacionado a essas atividades (implementado em meados dos anos 1970 em âmbito estadual, inicialmente no Rio de J aneiro e em São Paulo) foi necessário a adoção de padrões de emissão de efluentes líquidos e gasosos, visando assegurar a qualidade da água e do ar.

A crítica de Monosowski (1989, p. 19) deixa claro que a política de controle de poluição industrial implementada pelos militares atua sobre certos efeitos do modelo de desenvolvimento, mas não o questiona. A estratégia privilegiou a solução de um problema (a poluição industrial), um agente (a indústria) e uma responsabilidade de controle (o Estado). Em síntese, a estratégia visava reduzir a emissão de poluentes de modo a atingir padrões pré-fixados - caracterizando uma negociação restrita entre empresas privadas e órgãos públicos, sem questionamento quanto ao modelo de industrialização, sobretudo quanto à localização de empreendimentos potencialmente impactantes ao meio ambiente e também quanto às tecnologias empregadas.

Como se sabe, o problema da poluição industrial manifesta-se logo a curto prazo nas áreas em que este setor mais se concentra. Como a política ambiental adotada nos anos 1970 foi específica para determinados setores industriais no Brasil, ela não abrangeu as regiões menos povoadas, negligenciou os impactos ambientais de longo prazo, agindo em um "espaço fragmentado, considerado como uma sucessão de pontos isolados" (Monosowski, 1989: 19).

\section{A Terceira Abordagem Estratégica da Política Ambiental: o planejamento territorial}

O início da abordagem estratégica de planejamento territorial foi demarcado pela adoção do conceito de "área crítica de poluição" - no escopo do II PND (1974). Este fato introduziu uma primeira diferenciação espacial na regulação do modo de utilização e apropriação do meio ambiente no Brasil (Monosowski, 1989). Em suma, a estratégia consistia basicamente na delimitação de áreas industriais destinadas à instalação de atividades poluidoras² .

A grandeinovação a se destacar nesta etapa foi a utilização de critérios ecológicos para a definição e delimitação das áreas industriais nas principais regiões metropolitanas - fato que restringiu a abrangência da estratégia à essas regiões (já antropizadas). Ademais, a estratégia não alcançou as Políticas, Planos, e Programas governamentais na esfera federal. Apesar de algumas iniciativas

\footnotetext{
2 Sob o ponto de vista formal, a estratégia política de "planejamento territorial" pode ser exemplificada pelas leis metropolitanas de zoneamento industrial e de proteção de mananciais, e dos planos de zoneamento e uso do solo para proteção de bacias hidrográficas. De acordo com Sánchez (2008a), os primeiros planos de uso do solo no Brasil são datados de meados dos anos 1970. Eles procuravam ordenar formas de ocupação do espaço eminentemente urbano.
} 
setoriais isoladas ${ }^{3}$, os grandes projetos de infraestrutura implementados no período militar não tiveram questionamentos institucionais quanto à sua localização ou à tecnologia empregada, ou seja, não foram objeto de licenciamento ambiental.

Enquanto o espaço urbano tornou-se alvo de regulação, o espaço rural permaneceu aberto a todas as formas de apropriação para o desenvolvimento da atividade produtiva. Utilizando o conceito de racionalidade instrumental e racionalidade ambiental, Monosowski (1989) explica essa aparente omissão pelos diferentes papéis que assume o espaço no contexto econômico. No espaço urbano, as possibilidades de se promoverem modificações estruturais eficazes do ponto de vista ecológico são limitadas. Não sendo compreendido pela estratégia de planejamento territorial adotada nesta fase da política ambiental brasileira (notadamente urbana) o espaço rural se prestou às formas de apropriação mais rentáveis no curto prazo. Assim, "a racionalidade econômica instrumental, baseada no livre jogo das forças do mercado, pode manifestar-se em sua amplitude, em detrimento da consideração das perspectivas de longo prazo, caracterizando uma racionalidade ambiental" (Monosowski, 1989: 21).

A ausência de planejamento espacial abre possibilidade para o uso e para a apropriação dos recursos naturais da maneira mais rentável no curto prazo. Neste horizonte de tempo, as ações de mitigação e controle - contempladas nos procedimentos do licenciamento ambiental, por exemplo - são suficientes para atenuar os efeitos negativos de se apropriar dos recursos naturais de forma desordenada, e desvinculada de qualquer instrumento de planejamento de longo prazo $^{4}$.

Apesar de Monosowski (1989) ter classificado esta como uma fase da política ambiental brasileira, o planejamento territorial nunca fez parte efetivamente dos mecanismos de gestão ambiental de forma integrada, em âmbito nacional ${ }^{5}$. Pois tal política ficou restrita às regiões metropolitanas, ou a iniciativas setoriais, não sendo absorvida, em regra, pelas estratégias governamentais de desenvolvimento.

\footnotetext{
3 Na década de 1970 algumas agências internacionais de financiamento já solicitavam estudo prévio de impacto ambiental como critério para aprovação de projetos. Neste contexto, o Banco Mundial passou a exigir a realização de avaliações de impactos ambientais (AIA) para o financiamento de grandes projetos hídricos, por exemplo. Tal inovação provocou uma mudança institucional significativa no setor de energia do país, pois a ELETROBRÁS instituiu, a partir de 1974, a exigência desse tipo de estudo para implementação de usinas hidrelétricas (Monosowski, 1989).

${ }^{4}$ Infere-se que a dissociação entre as políticas ambientais e os mecanismos de planejamento de longo prazo (característica observada sistematicamente nas políticas públicas brasileiras), explica a importância atribuída ao licenciamento ambiental como instrumento regulador das relações de apropriação dos recursos naturais para a produção com o advento da Política Nacional do Meio Ambiente.

${ }^{5}$ A ausência de "cultura de planejamento" é um aspecto institucional (ligada aos hábitos de pensamento) marcante na sociedade brasileira. A característica aventureira (imediatista) do brasileiro foi bem explorada por Buarque de Holanda (1979). Este traço remete à formação do povo brasileiro e suas origens ibéricas. De acordo com o autor, o "aventureiro" despreza os esforços que não visam um proveio material imediato.
} 
Todavia, a partir dos anos 1980 observam-se alguns dispositivos legais com abrangência nacional que utilizam, pelo menos formalmente, a estratégia do "planejamento territorial" inaugurada nos anos 1970. Vale destacar o Plano Nacional de Gerenciamento Costeiro, criado pela Lei Federal no $\mathbf{0}$.7661, de 16 de maio de 1988; o Zoneamento Ecológico-econômico (ZEE), regulamentado pelo Decreto n⿳⺈ 4.297, de 10 de julho de 2002; e o Estatuto da Cidade, criado pela Lei no 10.257, de 10 de julho de 2001(Sánchez, 2008a: 77).

\section{A Quarta Abordagem Estratégica da Política Ambiental: a Política Nacional de Meio Ambiente}

Transcorridos os importantes debates que embasaram uma mudança de conscientização ambiental no mundo durante a década de 1970, uma nova fase da política ambiental brasileira foi iniciada em 1981 com a publicação da Lei no 6.938, que estabelece os objetivos, as ações e os instrumentos da política ambiental brasileira. Na categorização de Monosowski (1989) esta fase é especificada pela gestão integrada dos recursos naturais, expressa pela primeira vez em uma Política Nacional de Meio Ambiente (PNMA) formalmente instituída. Esta Lei absorve todas as abordagens estratégicas apresentadas nas seções anteriores. Envolvendo, inclusive, os aspectos institucionais, tais como a racionalidade eas práticas que caracterizaram a relação entre a produção eo meio ambiente em cada etapa.

Dentre as principais inovações trazidas pela Lei vale destacar a criação do Conselho Nacional do Meio Ambiente (CONAMA), propiciando a participação pública nas decisões relacionadas à temática ambiental. E também a criação do Sistema Nacional de Meio Ambiente (SISNAMA) com a função de articular o conjunto de instituições cujas atividades se relacionam com a proteção e melhoria da qualidade ambiental nas três esferas de governo.

O dispositivo legal também inovou ao inaugurar uma nova etapa no modo de utilização eapropriação dos recursos naturais para atividade produtiva, prevendo a utilização de instrumentos de gestão ambiental (Art. 9o da PNMA) de alcance nacional. Dentre eles, destacam-se: o estabelecimento de padrões de qualidade ambiental, o zoneamento ambiental, a avaliação de impactos ambientais, e o licenciamento de atividades efetiva ou potencialmente poluidoras.

Entretanto, é importante destacar neste ponto que, dentre aqueles instrumentos previstos na PNMA, o licenciamento ambiental (LA) foi adotado como a principal ferramenta de gestão responsável por disciplinar a forma como os recursos naturais seriam utilizados e adequados para a produção. Confirmando essa tendência, outros instrumentos previstos na Lei $\mathrm{n}^{\circ} 6.938 / 81$, como $o$ estabelecimento de padrões de qualidade e a avaliação de impacto ambiental foram incorporados aos procedimentos do licenciamento ambiental. O zoneamento ambiental representa uma possibilidade de implementação de um mecanismo de inserção da variável ambiental no sistema de planejamento em momento anterior à concepção de projeto. Entretanto, esta ferramenta ainda não figura dentre os procedimentos que envolvem as decisões sobre localização de atividades potencialmente impactantes no país.

Um avanço institucional importante nesse período foi a promulgação da atual constituição em 1988, que passa a conter capítulo específico sobre meio 
ambiente. Vale destacar o caput do artigo 225 e alguns itens do parágrafo $1^{\circ}$ para algumas considerações:

Art. 225. Todos têm direito ao meio ambiente ecologicamente equilibrado, bem de uso comum do povo e essencial à sadia qualidade de vida, impondo-se ao poder público e à coletividade o dever de defendê-lo e preservá-lo para as presentes e futuras gerações.

$\S$ 1o - Para assegurar a efetividade desse direito, incumbe ao poder público: [...] IV - exigir, na forma da lei, para instalação de obra ou atividade potencialmente causadora de significativa degradação do meio ambiente, estudo prévio de impacto ambiental, a que se dará publicidade; [...] (grifo nosso).

A inovação a se destacar é a preocupação com as gerações futuras expressa na Constituição Federal de 1988. Embora no primeiro momento possa não ter representado mudança significativa na formulação de políticas públicas, essa previsão constitucional tem a propriedade de conduzir a adoção de instrumentos de gestão ambiental dotados de maior capacidade para conciliar o desenvolvimento econômico e a disponibilidade dos recursos naturais no longo prazo.

De uma forma geral, no capítulo sobre meio ambiente, a Constituição de 1988 praticamente repete a mesma abordagem expressa na Política Nacional do Meio Ambiente em 1981. Ao exigir estudo prévio de impacto ambiental para instalação de obra ou atividade potencialmente causadora de degradação do meio ambiente, o legislador alcança apenas a avaliação ambiental de projetos - nível menos abrangente no sistema de planejamento ${ }^{6}$. Essa abordagem caracteriza uma gestão ambiental voltada predominantemente ao curto prazo, pouco articulada com os níveis decisórios capazes de integrar aspectos ambientais positivamente ao processo de desenvolvimento.

Monosowski (1989) destaca o caráter conservacionista da Carta Magna, especialmente por enfatizar aspectos de restrição ao uso de determinados recursos e espaços, e pouco elaborados quanto à utilização das potencialidades naturais para o desenvolvimento. A autora ressalta também a manutenção do diacronismo em relação às políticas de desenvolvimento. As medidas propostas não visavam orientar o planejamento econômico, constituindo-se numa reação aos seus efeitos. Na ocasião, já se identificavam problemas nos procedimentos do licenciamento ambiental, pelo fato desse instrumento retardar a avaliação de impacto para um momento quando as decisões já teriam sido tomadas, expondo sua limitação enquanto ferramenta de planejamento.

Percebe-se que nesta fase foram previstas importantes inovações técnicas e institucionais na legislação ambiental. Entretanto, estas não foram implementadas naquele momento por diversas questões. Com destaque para a crise econômica7 que marcou os anos de 1980, impedindo o Estado de realizar os

6 Os sistemas de planejamento são estruturados em “níveis de decisão”. O nível hierárquico menos influente é o de projetos, seguidos de programas, em terceiro estágio os planos e, por fim, o mais influente é a formulação de políticas (Wood; Dejeddour, 1992).

7As décadas subsequentes ao II PND foram marcadas pela desaceleração no ritmo de crescimento econômico. A estagnação e as altas taxas de inflação são as principais características da economia brasileira nos anos 1980. Em 1988, a renda per capita era inferior à de 1980. Em suma, a situação 
investimentos necessários para promover tais reformas institucionais. Por outro lado, a queda nos investimentos em infraestrutura refletiu na baixa demanda por serviços ambientais. Somando-se a carência de recursos, face à crise econômica, observou-se uma lentidão do Estado em realizar os investimentos em estrutura de regulação pública necessários para institucionalizar importantes instrumentos de gestão ambiental previstos na PNMA.

\subsection{A consolidação da Política Nacional do Meio Ambiente}

Até aqui foram analisadas quatro abordagens estratégicas básicas utilizadas no processo de evolução das políticas ambientais brasileiras. Como já enfatizado, essa pesquisa foi amparada principalmente na categorização desenvolvida por Monosowski em 1989. Naquela época a política ambiental brasileira, embora já formalizada, não havia sido implementada de fato. Vários dispositivos careciam de regulamentação, e não havia capacidade técnica e institucional para pôr em prática os instrumentos previstos em lei. Por isso, faz-se necessário apresentar alguns aspectos do processo de institucionalização de determinados instrumentos da Lei no 6.938/81- aqueles considerados relevantes no âmbito da problemática em questão.

Além da publicação da Política Nacional do Meio Ambiente, a promulgação da Constituição Federal em 1988 também não representou de imediato uma mudança na regulação da atividade produtiva e os impactos ambientais a ela associados. Como já observado, grosso modo, o texto constitucional repetiu os mecanismos de gestão ambiental previstos da PNMA - quais sejam, os instrumentos de política ambiental que careciam de regulamentação. Será observado que o licenciamento ambiental, por exemplo só foi regulamentado efetivamente em âmbito nacional no fim da década de 1990, e o Zoneamento Ecológico-Econômico ainda está em fase de implementação. Ademais, por motivos já salientados na seção anterior, em 1981, o Estado não contava com instituições competentes para executar a PNMA.

Considera-se uma tarefa quase aleatória a tentativa de definir um marco que caracterize uma nova abordagem estratégica nas políticas ambientais brasileiras posterior à 1981. Visto que após a publicação da Política Nacional do Meio Ambiente não surgiu no ordenamento jurídico brasileiro nenhum mecanismo de gestão ambiental diferente daqueles previstos na lei. Mas sim, regulamentos e instituições que possibilitaram a execução desses instrumentos.

Logo, é possível afirmar que a abordagem estratégica predominante depreendida a partir de 1981 continua sendo a Política Nacional do Meio Ambiente, que expressa uma gestão integrada dos recursos naturais. Outrossim, o caráter permanente da política ambiental brasileira mantém latente todas as abordagens estratégicas apresentadas neste trabalho. Isto posto, esta seção enfatiza a ratificação do licenciamento ambiental como principal instrumento de gestão incumbido de avaliar a compatibilidade entre produção e preservação ambiental

nessa década foi caracterizada por um importante cenário de desinvestimento, crise fiscal e aumento da dívida externa, que para ser paga impulsionava também aumento da dívida interna (Bresser-Pereira, 1991). 
no Brasil. Essa avaliação é realizada na fase inicial do processo de licenciamento, quando se decide sobre a localização e tecnologia associada à produção.

Portanto, passados oito anos após a formalização da PNMA, foi criado em 1989 o Instituto Brasileiro do Meio Ambiente e dos Recursos Naturais Renováveis (IBAMA). A nova instituição alcança um escopo muito mais abrangente do que as competências institucionais da SEMA, uma vez que assumiu as atribuições dos diversos órgãos, antes responsáveis pela execução da política ambiental de forma fragmentada.

Durante a década de 1980, o atraso na implementação de alguns instrumentos previstos na PNMA foi atribuído à crise econômica enfrentada naquele período. No decênio seguinte a situação não foi muito diferente. No início da década de 1990, o principal vilão da economia brasileira foi a inflação (Bresser-Pereira; Gonzalez; Lucinda, 2008). Este problema teve solução encaminhada a partir do Plano Real em 1994, que abortou a rota da alta inflação e da hiperinflação brasileira, e proporcionou a estabilidade dos níveis de preços no Brasil. Se por um lado a inflação estava sob controle, de outro, a Dívida Líquida do Setor Público (DLSP) em relação ao Produto Interno Bruto (PIB) aumentava aceleradamente devido ao esforço em manter o câmbio fixo. Para estes fins, adotava-se uma política monetária contracionista: aumentava-se a taxa de juros e a autoridade monetária atuava comprando e vendendo divisas com as reservas internacionais (Batista J r., 2002). Em suma, na década de 1990, o cenário econômico também não foi favorável à continuidade dos investimentos na indústria nacional e na ampliação e aprimoramento da infraestrutura logística nacional. É razoável inferir que, da mesma forma como ocorrido na década anterior, a falta de demanda por serviços ambientais talvez não tenha estimulado a corrida pela regulamentação dos instrumentos de regulação nesta área.

Nesse sentido, vale registrar que o estabelecimento de uma política ambiental demanda distribuição de recursos, criação de instituições públicas eficientes, responsáveis e bem gerenciadas. Entretanto, razões ideológicas, crise da dívida externa, desequilíbrios fiscais e necessidade de reestruturação produtiva exportadora, a tendência e as pressões nacionais e internacionais ecoam no sentido de reduzir gasto público e especialmente investimentos. Nessas condições, é ilusório propor um aumento nos gastos para a preservação do meio ambiente (Sunkel, 2001).

Mesmo diante desse quando, algum avanço foi percebido no plano institucional. A obediência às exigências da legislação ambiental por parte das instituições do poder público cresceu progressivamente a partir da década de 1990. Essa mudança pode ser atribuída, em parte, à aprovação da Lei de Crimes Ambientais, em 1998, que passou a considerar crime o funcionamento de atividades potencialmente poluidoras sem a devida licença ambiental. E também à intensificação gradativa da atuação do Ministério Público visando o cumprimento da lei (Teixeira, 2008).

Outro avanço importante foi a efetiva regulamentação do licenciamento ambiental com a publicação da Resolução Conama no 237/97. Este dispositivo promoveu a uniformização e delimitação das atividades sujeitas ao processo de licenciamento; e também definiu critérios para a definição de competência para execução do licenciamento. Essa Resolução completa o conjunto de normas que 
permitiram a efetiva institucionalização do licenciamento ambiental como procedimento utilizado, em última instância, para avaliar viabilidade ambiental de projetos potencialmente causadoras de impactos ambientais. Portanto, a partir do fim da década de 1990 foi possível estabelecer em âmbito nacional o monitoramento e controle das atividades contempladas no rol taxativo previsto naquela Resolução, objetivando a mitigação e prevenção de impactos ambientais.

Como verificado, a Política Nacional do Meio Ambiente teve sua implementação iniciada em um período de baixo investimento. Até o início dos anos 2000, o principal instrumento de gestão ambiental previsto legalmente (o licenciamento ambiental) não havia sido sistematicamente empregado no plano federal. A escassez de projetos produtivos e relacionados à infraestrutura nas décadas de 1980 e 1990 adiaria para a década seguinte a aplicação em larga escala do instrumento. Até o início do século XXI, o último "projeto desenvolvimentista" 8 implementado no país, padeceu junto com o "sonho prussiano"9 de Geisel com o fim do II PND, quando a política ambiental brasileira estava em fase de maturação. Obviamente aqueles projetos, por terem sido desenvolvidos nos anos 1970, não foram objeto de licenciamento ambiental. Nas duas décadas seguintes a situação era quase inversa: PNMA já havia sido formalizada em 1981, mas não havia um "projeto desenvolvimentista" nos moldes do II PND, nem mesmo um conjunto de projetos potencialmente impactantes ao meio ambiente que demandassem urgência na implementação demecanismos regulatórios previstos na PNMA - fator que influenciou na lenta institucionalização e aperfeiçoamento dos instrumentos de gestão ambiental previstos na legislação.

O cenário econômico mundial no início do século XXI foi marcado por uma expansão econômica impulsionada pelo rápido crescimento asiático, provocando alta nos preços de commodities, fenômeno que beneficiaria economias cuja base produtiva fossem voltadas à exportação de produtos primários, como foi o caso do Brasil. O ambiente foi propício à implementação de política econômica expansionista (Werneck, 2014). Nesse sentido, a partir de 2004 verificou-se a atuação do governo como indutor da oferta de ampliação e modernização da infraestrutura logística do país. Disso decorreu um aumento exponencial da demanda de serviços ambientais dos órgãos licenciadores ${ }^{10}$.

\footnotetext{
8 Este termo é empregado aqui com ressalva, pois o esforço comandado pelo então presidente Ernesto Geisel na década de 1970 era voltado principalmente à industrialização. Entretanto, o conceito de desenvolvimento envolve mudanças estruturais na sociedade, muito mais amplas do a implantação de uma base industrial. O desenvolvimento compreende uma transformação do elemento humano e de seu ambiente social (Pepelasis; Mears; Adelman, 1961).
}

${ }^{9}$ A esse respeito consultar Fiori (1990).

10 Para exemplificar, vale observar a evolução do número de processos delicenciamento ambiental instaurados no Ibama em períodos distintos: no ano de 1989 haviam três processos de licenciamento ambiental na recém-criada autarquia. Em 2003, esse número subiu para 486 processos, no ano de 2010 já haviam 1416 e em 2013, 1854 processos de licenciamento ambiental conduzidos em nível federal. Isto representou um aumento de aproximadamente 190\%, em dez anos, na demanda por avaliação de impactos de projetos cuja competência para licenciar cabe à União (essas informações foram obtidas no SISLIC - Sistema de Licenciamento Ambiental Federal, plataforma que sistematiza os dados dos processos de licenciamento ambiental 
A essa altura o Licenciamento Ambiental já estava regulamentado, e os órgãos licenciadores foram gradativamente adequados para responder ao aumento da demanda. Atualmente, não é possível, em regra, a instalação ou operação de empreendimentos ou atividades potencialmente impactantes ao meio ambiente sem que se obtenha autorização expressa nesse sentido. Dessa forma, a grande maioria dos grandes projetos relacionados ao Programa de Aceleração do Crescimento (PAC), implementado a partir de 2007, foram submetidos ao crivo do licenciamento ambiental. Diferente do que ocorreu no âmbito do II PND no governo Geisel, e nos "projetos desenvolvimentistas" promovidos nos governos dos presidentes Getúlio Vargas eJ uscelino Kubitschek. Entretanto, estes têm algo em comum com o PAC. Via de regra, em nenhuma dessas fases, os projetos produtivos foram orientados por planejamento estratégico de longo prazo. As questões ambientais nunca foram sistematicamente consideradas previamente (ex ante) nas etapas de concepção dos grandes projetos produtivos no Brasil. Nem de forma indutiva, explorando potencialidades, nem restritiva, considerando os limites ecológicos e socioeconômicos.

Ressalva-se que nesse estágio algumas agendas tenham conseguido aprimorar sua gestão ambiental de longo prazo. Como o caso, por exemplo, do setor de energia, que conta com mecanismos institucionais para planejar a oferta de acordo com os estudos de demanda - Plano Decenal de Expansão de Energia ${ }^{11}$.

As iniciativas setoriais de planejamento estratégico são louváveis, entretanto, se não forem "apresentadas como resposta ou para atendimento de alguma exigência legal" (Sánchez, 2008b: 1), elas não vinculam a decisão do órgão licenciador. Ou seja, o fato de uma hidrelétrica, ou uma ferrovia terem sido concebidas a partir de um planejamento setorial, mesmo que a variável ambiental tenha sido observada naquela instância, não implica que o empreendimento terá sua viabilidade ambiental assegurada perante o órgão licenciador, onde a análise é restrita ao nível de projeto.

Convém salientar que, apesar de se tratar de um mecanismo de gestão de curto prazo, a avaliação ambiental de projetos não é procedimento dispensável. Nesse horizonte, o licenciamento ambiental é adequado para promover o monitoramento, controle, mitigação e prevenção de impactos ambientais resultantes associados à produção. Porém, devido à ausência de dispositivo institucional voltado a articular as questões ambientais em nível estratégico (por exemplo, na formulação de políticas públicas) nota-se que a sociedade deposita no licenciamento expectativas que não lhe competem, colocando o instrumento em descrédito (Pellin et al., 2011).

conduzidos no âmbito federal - através do site: 〈http://www.ibama.gov.br/sistemas/sislic > Acesso em novembro de 2016).

11 No setor energético, compete ao Conselho Nacional de Política Energética - CNPE o estabelecimento de políticas e diretrizes, visando ao desenvolvimento nacional sustentado. Os Planos Decenais elaborados no setor elétrico constituem um dos principais instrumentos de planejamento da expansão eletro-energética do país. A partir de 2007 estes planos ampliaram a abrangência dos seus estudos, incorporando uma visão integrada da expansão da demanda e da oferta de diversos energéticos, além da energia elétrica (EPE, 2015). 
A princípio, condicionar a execução de obras ou atividades à avaliação ambiental de projeto representou um grande avanço no início da década de 1980 - quando o quadro institucional não contava com mecanismo sistemático de regulação ambiental das atividades produtivas. Naquele momento, a ideia de desenvolvimento sustentável (na época ainda conhecido como ecodesenvolvimento) era incipiente, e carente de uma base teórica sólida para superar a lógica ortodoxa, que trata as variáveis ambientais como externalidades do desenvolvimento (Leff, 2006), e construir um novo paradigma produtivo fundamentado nos limites biofísicos do ecossistema e em aspirações além do curto prazo.

Mas o longo das décadas de 1980 e 1990 surgiram novas elaborações em torno da concepção de desenvolvimento sustentável, e propostas práticas despontaram nesse caminho ${ }^{12}$. Contudo, o processo de institucionalização da PNMA foi tão lento que quando o modelo de gestão se consolidou, no fim dos anos 1990, ele já não se adequava aos novos desafios do desenvolvimento e da sustentabilidade. Notou-se uma grande dificuldade em flexibilizar as instituições no sentido de endogeneizar a dimensão ambiental no processo de planejamento do desenvolvimento no Brasil - o que seria oportuno no momento de reconstrução das instituições públicas nacionais pós-ditadura.

6 Considerações Finais

A análise do processo de evolução das políticas ambientais apresentadas neste artigo destaca as circunstâncias que determinaram o predomínio das estratégias que contornaram a relação entre produção e meio ambiente no Brasil, especialmente os aspectos históricos e institucionais. A exemplo disso, a etapa de "administração dos recursos naturais", iniciada nos anos 1930, refletia uma visão de sistema econômico pouco integrado com as questões ambientais. As ações eram voltadas a disciplinar o acesso aos insumos necessários para a promoção de uma industrialização intensiva em recursos naturais, assim como na fase do "controle de poluição industrial", inaugurada nos anos 1970. Nesta etapa observou-se que a repercussão das ideias e discussões resultantes da Conferência de Estocolmo influenciou o surgimento do primeiro órgão ambiental brasileiro voltado exclusivamente à questão ambiental - a Secretaria Especial de Meio Ambiente, criada em 1973, um ano após àquela Conferência. Por outro lado, a estratégia de "planejamento territorial" poderia conduzir a uma política ambiental mais integrada com o processo de planejamento de longo prazo. Todavia, tal política nunca fez parte efetivamente dos mecanismos de gestão ambiental em âmbito nacional. Esta estratégia, percebida no contexto do II PND, ficou restrita às regiões metropolitanas, não sendo absorvida, em regra, pelas ações governamentais visando o "desenvolvimento". Notou-se também que mesmo com o advento das etapas seguintes, a estratégia política precedente não desaparecia completamente. Elas foram se sobrepondo, revelando o caráter

12 Na ocasião da Conferência das Nações Unidas sobre o Meio Ambiente e Desenvolvimento celebrada no Rio de J aneiro, em 1992 - foi elaborado um programa global (conhecido como Agenda 21) para dar institucionalidade e legitimidadeàs políticas de desenvolvimento sustentável (Leff, 2006). 
"permanente" das abordagens estratégicas predominantes da política ambiental brasileira.

A evolução dessas estratégias sobrepostas resultou na formulação da Política Nacional do Meio Ambiente formalizada em 1981. Contudo, a regulamentação dos instrumentos de regulação ambiental previstos na política não ocorreu de imediato. Dentre outros fatores, a crise econômica vivenciada nas décadas de 1980 e 1990 retardaram a implantação dos principais mecanismos de regulação. Recorrendo às lições de Sunkel (2001), é inócuo propor aumento de gastos para preservação do meio ambiente em um cenário de crise financeira, desequilíbrios fiscais e necessidade de reestruturação da estrutura produtiva exportadora. Nessas condições, as pressões nacionais e internacionais convergem no sentido de induzir à redução de gasto público e dos investimentos.

Constatou-se que dos dispositivos previstos na PNMA o licenciamento ambiental se consolidou como instrumento de gestão encarregado de regular a relação entre produção e meio ambiente, assegurando a prevenção e o controle dos impactos ambientais resultantes do processo produtivo. Considerando que o cenário anterior à vigência da PNMA era caracterizado por uma ausência desse tipo de instrumento em âmbito nacional, condicionar a execução de obras ou atividades à avaliação ambiental do projeto representou um enorme progresso. Entretanto, o modelo de gestão ambiental voltado a regular projetos, portanto com o horizonte restrito ao curto prazo, apresenta importantes limitações. Especialmente devido à ausência de mecanismos capazes de incorporar potencialidades e restrições ambientais no sistema de planejamento em momento anterior à concepção de projetos. Essa característica torna a gestão ambiental praticada no Brasil desvinculada das estratégias de desenvolvimento. É preciso, portanto, superar a falta de visão holística, reflexo da carência de uma "cultura de planejamento", para transpor a estrutura economicista e moldar instituições capazes de integrar a dimensão ambiental em etapa adequada no sistema de planejamento, favorecendo o desenvolvimento socioeconômico do País.

\section{Referências Bibliográficas}

BatistaJ J., B. J (2002). A Economia como Ela é. São Paulo: Boitempo Editorial.

Brasil. (1973). Decreto ${ }^{\circ}$ 73.030, 30 de outubro de 1973. Cria, no âmbito do Ministério do Interior, a Secretaria Especial do Meio Ambiente - SEMA, e dá outras providências. Disponível em: $<$ http:// www2.camara.leg.br/ legin/ fed/decret/ 1970-1979/decreto-7303030-outubro-1973-421650-publicacaooriginal-1-pe.html>. Acesso em: out/2016.

Brasil. (1981). Lei no 6.938, de 31 de agosto de 1981. Dispõe sobre a Política Nacional de Meio Ambiente, seus fins e mecanismos de formulação e aplicação, e dá outras providências. Disponível em: < http://www.planalto.gov.br/ccivil_03/Leis/L6938.htm>. Acesso em: nov/2016. 
Brasil. (1988). Constituição da República Federativa do Brasil de 1988. Disponível em <http:// www.senado.gov.br/atividade/const/constituicaofederal.asp\#/>. Acesso em: nov/ 2016.

Bresser-Pereira, L. C. (1991). “A Lógica Perversa da Estagnação: dívida, déficit e inflação no Brasil". Revista Brasileira de Economia 45(2), pp. 187-211.

Bresser-Pereira, L. C.; Gonzales, L.; Lucinda, C. (2008). Crises Financeiras nos Anos 1990 e Poupança Externa. Belo Horizonte: Nova Economia, v. 18, n. 3, p. 327.

Buarque de Holanda, S. (1979). Raízes do Brasil. 13aㅡ ed. Rio de Janeiro: José Olympio.

Castro, A. D.; Souza, F. E. P. D. (1985). A Economia Brasileira em Marcha Forçada. Rio de J aneiro: Paz e terra, v. 32.

Cunha, L. H.; Coelho, M. C. N. (2007). "Política e Gestão Ambiental”. In: Cunha, S. B.; Guerra, A. J. T (org.). A Questão Ambiental: diferentes abordagens. 3. ed. Rio de J aneiro: Bertrand Brasil.

EPE - Empresa de Pesquisa Energética (2015). Plano Decenal de Expansão de Energia 2024. Brasília: Ministério de Minas e Energia/EPE.

Fiori, J . L. (1990). “Sonhos Prussianos, Crises Brasileiras: leitura política de uma industrialização tardia”. Porto Alegre: Ensaios FEE, 11(1): 41-61.

Furtado, C. (1959). Formação Econômica do Brasil. Rio de J aneiro: Fundo de Cultura.

Leff, E. (2006). Racionalidade Ambiental: a reapropriação social da natureza. Rio de J aneiro: Civilização Brasileira.

Monosowski, E. (1989). "Políticas ambientais e desenvolvimento no Brasil”. São Paulo: Cadernos FUNDAP, págs. 15-24.

Orenstein, L; Sochaczewski, A. C. (2014). "Democracia com Desenvolvimento, 1956-1961". In: Abreu, M. P. (org.) A Ordem do Progresso: dois séculos de política econômica no Brasil. 2. ed. Rio deJ aneiro: Elsevier.

Pellin, A.; Lemos, C. C.; Tachard, A.; Oliveira, I. S. D.; Souza, M. P. (2011). "Avaliação Ambiental Estratégica no Brasil: considerações a respeito do papel das agências multilaterais de desenvolvimento". São Paulo: Eng. Sanit. Ambient., v.16 n.1, p.27-36.

Pepelasis, A.; Mears, L.; Adelman, I. (1961). Determinantes do Desenvolvimento Econômico. São Paulo: Atlas.

Sachs, I. (2008). Caminhos para o Desenvolvimento Sustentável. 3. ed. Rio de J aneiro: Ed. Garamond.

Sánchez, L.E. (2008a) Avaliação de Impacto Ambiental: conceitos e métodos. São Paulo: Oficina de Textos.

Sánchez, L.E. (2008b). Avaliação Ambiental Estratégica e sua Aplicação no Brasil. Texto preparado como referência para o debate "Rumos da Avaliação Ambiental Estratégica no Brasil". São Paulo: Instituto de Estudos Avançados da Universidade de São Paulo. 
Sunkel, O.; PAZ, P. (1974). Os Conceitos de Desenvolvimento e Subdesenvolvimento. Rio de J aneiro: Forum Editora.

Sunkel, O. (2001). "A sustentabilidade do desenvolvimento atual". In: Arbix, G.; Zilbovicius, M.; Abramovay, R. (orgs.). Razões e Ficções do Desenvolvimento. São Paulo: Editora UNESP \& EDUSP, pp. 267-310.

Teixeira, I. M. V. (2008). O Uso da Avaliação Ambiental Estratégica no Planejamento da Oferta de Blocos para Exploração eProdução dePetróleo e Gás Natural no Brasil: uma proposta. Rio de J aneiro: tese de doutorado, UFRJ, COPPE, D.Sc., Programa de Planejamento Energético.

Wermeck, R. L. F. (2014). "Alternância política, redistribuição e crescimento, 2003-2010". In: ABREU, M. P. (org.) A Ordem do Progresso: dois séculos de política econômica no Brasil. 2. ed. Rio de J aneiro: Elsevier.

Wood, C.; Dejeddour, M. (1992). "Strategic environmental assessment: EA of policies, plans and programmes." UK: Impact Assessment, 10:1, pp. 3-22. 